\title{
CERVANTES, EL CAUTIVERIO Y LOS RENEGADOS
}

El 26 de septiembre de 1575 fue tomada la galera El Sol, en que viajaba Cervantes, por las fuerzas del cosario renegado Arnaute Mamí. A Cervantes le llevaron preso a Argel, donde quedó casi cinco años. Rescatado el 19 de septiembre de 1580, partió para España el 24 de octubre del mismo año. Ninguna experiencia vivida por Cervantes ha dejado huellas más duraderas en su obra que estos largos años de cautiverio en el norte de África, en ese Argel tan rico en diversidad humana y religiosa - turcos, moriscos, bereberes, griegos, italianos, españoles, judíos, eslavos, todos con su idioma y su ropa distintivos - en el que el estado musulmán no vedaba la práctica del judaísmo o del cristianismo, cosa que desde 1492 no se había visto en España, convertida, en la superficie por lo menos, en un país unámimamente católico.

Prosperaba Argel gracias al botín tomado por sus galeotas de cosarios, botín que incluía a los cautivos, cuyos patrones o amos esperaban recibir sumas cuantiosas de dinero por su rescate (por Cervantes se pidieron quinientos ducados), o si no hubiera tal esperanza, de lo que ganaban los cautivos trabajando en la ciudad, o el precio de su venta en el mercado de esclavos. Cervantes cuenta 20000 cautivos en 1577 en la "Epístola a Mateo Vázquez", cifra que se reduce a 15000 en El trato de Argel".

En sus años de cautiverio Cervantes observó con enorme curiosidad las costumbres de árabes y turcos - desde el modo de comer hasta el trato de las mujeres o la administración de la

1"Epístola a Mateo Vázquez", en Miguel de Cervantes, Obras completas. Comedias y entremeses. Poesias sueltas, eds. Rodolfo Schevill y Adolfo Bonilla, Gráficas Reunidas, Madrid, 1922, t. 6, p. 29, y El trato de Argel, en t. 5, p. 23. Todas las referencias siguientes a la obra de Cervantes remiten a la edición de Schevill y Bonilla, con la excepción de las citas del Quijote. Cuando no se trate de este último, sólo señalaré el número de página entre paréntesis.

NREH XI. (1999) ním 1 979-991 
justicia- y el dolor y temor de los cautivos. Todo esto pasó a sus escritos: cuatro comedias suyas (El trato de Argel, Los baños de Argel, El gallardo español y La gran sultana) se desarrollan en territorios islámicos; hay episodios en todas sus novelas que pintan ataques por cosarios contra cristianos -en el libro 50 de La Galatea Timbrio relata la captura de su navío por Arnaute Mamí; en el Persiles, libro $3^{\circ}$, cap. 10 , se vuelve a hablar del cautiverio en Argel, y en el siguiente capítulo se dramatiza el brutal ataque de dieciséis bajeles bereberes contra un pueblo de Valencia cuyos habitantes moriscos quieren huir con los bajeles para volver a su religión en Argel; el Quijote nos ofrece en el relato del Capitán Cautivo unas de las páginas más hermosas escritas por Cervantes relacionadas con la experiencia argelina - y dos de las novelas ejemplares (La española inglesa y especialmente El amante liberal) vuelven al Mediterráneo y los cosarios.

De todo lo que vio en Argel es obvio que una de las cosas más perturbadoras para él fue el enorme número de cristianos que habían renegado de su fe para seguir el Islam². Diego de Haedo, describiendo Argel en los mismos años del cautiverio de Gervantes, nos dice que de las 12200 casas de la ciudad, unas 6000 eran de renegados. Estos

...turcos de profesión son todos los renegados que siendo de sangre y de padres cristianos, de su propia voluntad se hicieron turcos [...] Estos y sus hijos por sí solos, son más que todos los otros vecinos moros y turcos y judíos de Argel, porque no hay nación de cristianos en el mundo de la cual no hay renegado y renegados en Argel... ${ }^{3}$

Y añade: "estos tales renegados son después todos los principales enemigos que el nombre cristiano tiene, y en los cuales está casi todo el poder, dominio, gobierno y riqueza de Argel y de todo su Reino"' (t. 1, p. 55).

Y esto era verdad; casi todos los oficiales importantes con quienes trató Cervantes eran renegados: por ejemplo, Arnaute Ma-

2 Casi siempre "renegado" se refiere a la persona que ha pasado del cristianismo al Islam, aunque había algún judío que siguió el mismo camino o algún musulmán que se hizo cristiano. Para un judío y un musulmán así, véase Diego de Haedo, Topografía e historia general de Argel, Sociedad de Bibliófilos Españoles, Madrid, 1929, t. 2, pp. 4-5 y t. 3, pp. 42-48. El primer tomo se publicó en 1927.

${ }^{3}$ Cf. Ibid, t. 1, pp. 43 y 55, e incluso halla renegados indios en el Nuevo Mundo. 
mí, renegado albanés, capitán de la flota de Argel, mandó las galeras de cosarios que tomaron El Sol; Dalí Mamí, renegado griego, cosario bajo el mando de Arnaute en esa ocasión, fue el patrón de Cervantes desde ese momento hasta la primavera de 1580 , cuando el cautivo fue comprado por Asán Bajá, el renegado veneciano que sirvió de gobernador o rey de Argel desde 1577 hasta septiembre de 1580 , y el cosario Morato Ráez Maltrapillo, renegado murciano, amigo de Asán Bajá, quien protegió a Cervantes y le salvó dos veces de duros castigos ${ }^{4}$. Por su parte, Haedo informa que en 1581 veintiuno de los treinta y cinco dueños de galeotas del corso eran renegados (t. 1, pp. 89-91).

Además, Cervantes había empleado en 1577 a un tornadizo llamado El Dorador (nació cristiano, se hizo musulmán, volvió al cristianismo, para después volver al Islam) en su segundo intento de fuga, El Dorador, cobarde y temeroso, reveló los planes a Asán Bajá en el último momento. En 1579, en el cuarto intento de fuga, Cervantes volvió a empleai a un renegado, esta vez de Andalucía, el licenciado Girón, de nombre islámico Abderrahmen, que quería regresar a España y reconciliarse con la Iglesia. Fueron delatados los planes no por el renegado sino por un cautivo cristiano, el sacerdote Juan Blanco de Paz (de orígenes oscuros, posiblemente judíos y moriscos).

Las páginas de Haedo relatan varios casos de renegados cristianos (como El Dorador empleado por Cervantes) que vuelven varias veces a España, donde se reconcilian con la Iglesia, sólo para después regresar a Argel y vivir como moros. Buenos ejemplos son las historias de Francisco de Almansa y Caur Alí, renegado griego, reconciliado en Valencia (t. 3, pp. 33 y 53).

El procedimiento para volver al cristianismo no parece haber sido difícil. En 1528 el Consejo de la Inquisición había decretado que ciertos clérigos de las fortalezas españolas del Peñón de Argel y de Bugía debían absolver a los renegados que venían huyendo de tierra de moros, en vista de que la conversión había sido forzada "por tormentos y mala vida". Luego los delincuentes así absueltos debían presentarse, tan pronto como fuera posible, “ . . . delante los Inquisidores del partido donde fueren naturales, confiando e siendo ciertos que los dichos Inquisidores los abraça-

\footnotetext{
${ }^{4}$ Para los detalles del cautiverio de Cervantes, véase William Byron, Cervantes. A Biography, Doubleday, New York, 1978, caps. 16-19. La transcripción al castellano de nombres árabes es caótica, cuando es posible, suelo seguir el uso de Haedo.
} 
rán y recibirán a misericordia y los tratarán muy benignamente sin les hazer vergüenza alguna"'5.

Ahora bien, el Peñón de Argel fue tomado en 1529 por Barbarroja, y Bugía fue ganado por los turcos en 1555. En tiempos de Cervantes la fortaleza cristiana más cercana a Argel era Orán, y los renegados que pensaban huir solían pedir a los cautivos cristianos cartas que dieran fe de la sinceridad de su cristianismo y del buen trato dado a los esclavos cristianos, para presentarlas después a los inquisidores. Así lo hace un renegado en Los baños de Argel y otro en el relato del Capitán Cautivo en el Quijote.

No sabemos cuántos renegados se aprovecharon del edicto de la Inquisición, ni tampoco se sabe si el proceso contra el renegado era tan benévolo como se prometía. Carecemos de estudios de tales procesos conservados en los archivos existentes de la Inquisición. Los casos de Almansa y Caur Alí citados más arriba parecen indicar que sí fue fácil la reconciliación, pero ¿la actitud del pueblo hacia el renegado reconciliado? De esto tampoco hay testimonio, pero en la comedia Los cautivos de Argel (escrita posiblemente en 1599, por la referencia a las bodas de Felipe III en ese año, puede que sea una refundición del Trato de Argel, quizá por Lope) se le advierte a un cristiano que piensa, como tantos, hacerse moro por un rato y luego volver a su primera fe, que si regresa puede estar seguro de ser despreciado por sus vecinos: “ . . Si me voy / a España, seré afrentado; / llamaránme el renegado, / afrenta a mis deudos soy; / nadie querrá andar conmigo" 6 . Lo que sí se sabe es que entre los renegados cristianos había muchos que se sentían todavía cristianos en el alma ${ }^{7}$, habiendo adoptado la religión y la indumentaria turcas sencillamente por miedo, o por el deseo de medrar, o (en el caso de los hombres) para gozar de más libertad sexual.

Detengámonos ahora un momento para considerar el cuadro de vida que Argel le presentaba a Cervantes en 1575-1580: lo que se destaca es la importancia de la religión, ligada con el orgullo de la patria (la España cristiana contra la Turquía islámica), jun-

${ }^{5}$ Todo el decreto se reproduce en Augustin Redondo, Antonio de Guevara (1480?-1545) et l'Espagne de son temps, Libraire Droz, Genève, 1976, pp. 229 230 , n. 56.

${ }^{6}$ Lope DE Vega, Obras, ed. de Emilio Cotarelo y Mori, Real Academia Española, Madrid, 1917, t. 4, p. 251 a.

7 Véase Diego de Haedo, op. cit., t. 1, p. 165, y Jaime Oliver Asín, "La hija de Agi Morato en la obra de Cervantes", $B R A ' E, 27$ (1947-48), pp. 252, 285 y 318. 
to con la gran dificultad de conocer el sentimiento religioso auténtico escondido en el corazón. La ropa decía turco, judío o moro; el alma decía cristiano o quizá ateo. Al judío renegado Mahamet, patrón del cautivo Dr. Antonio de Sosa, gran amigo de Cervantes, se le llama "impío ateo" que no aprueba ninguna secta o religión ${ }^{8}$. No sería el único así. Conocía Cervantes a renegados buenos, generosos, leales como Morato Ráez Maltrapillo y a cristianos malvados como Juan Blanco de Paz. ¿A qué punto firme atenerse en ese mar revoltoso?

En la primera obra suya que tiene que ver con el cautiverio, El trato de Argel (dividida en cuatro actos y escrita posiblemente en 1581 , tan cercana a la fecha de su rescate), se anuncia con profunda convicción varios temas o motivos que nunca abandona del todo. Primero, la presión en los cautivos para convertirse es dura, constante y peligrosa; así Aurelio, esclavo del renegado Isuf (Yzuf en el texto), debate consigo mismo alegando que la Necesidad y la Ocasión bien pueden forzar a muchos a renegar. Además, Cristo perdonará las ofensas cometidas por necesidad. Pero termina valientemente rechazando estos argumentos para proclamar: "¡Christiano soy, y e de viuir christiano!" 9 Otro cautivo cristiano, Leonardo (erróneamente llamado Pedro en el texto), explica a su amigo Sayavedra que piensa hacerse moro por un breve rato, arguyendo que convertirse es tan sencillo (sólo "retajarse y decir / ciertas palabras de Mahoma"); no hay que negar a Cristo, y en su intención quedará por dentro siempre cristiano. Este argumento, esgrimido por tantos renegados (y no sin parecido a la práctica de algunas sectas musulmanas de taquĩya, o el disimulo sistemático de la creencia íntima para protegerse en un clima hostil), lo refuta vehementemente Sayavedra en uno de los parlamentos más candentes del drama. Cristo requiere que sus fieles le confiesen ante los hombres (pp. 86-92). Leonardo no reniega. La lección más conspicua de toda la obra es, precisamente, "No renegar".

Segundo, se hace hincapié en la facilidad para persuadir ai niño, inocente de los preceptos de la fe, a convertirse, más por regalos y dádivas que por castigos; así ocurre con el niño Juanico, vendido como esclavo, que reniega para tener vestidos galanes y comida sabrosa. Ya se llama a sí mismo Solimán y a su hermano Francisco "perro" cristiano (pp. 73-75). Vale la pena recordar

${ }^{8}$ Diego de Haedo, op. cit., t. 2, p. 5.

${ }^{9} O C$, t. 5, p. 72 . 
algunos casos históricos de tales renegados convertidos cuando muy jóvenes: por ejemplo, Agi Morato, de padres cristianos eslavos, y Asán Bajá, nacido de padres cristianos en Venecia en $1545^{10}$.

Los renegados no ocupan un espacio muy importante en la obra, y ninguno es presentado como bueno. Uno, salido de la imaginación de Cervantes, es Izuf, patrón de Aurelio e identificado como renegado español. Otro es el histórico Asán Bajá (Azan en el texto), rey de Argel (de quien se ha hablado más arriba), quien, después de castigar cruelmente a un cautivo, pronuncia un elogio de la valentía del español (de "ánimo indomable", p. 45). Finalmente se relata la historia de un morisco renegado, cosario activo en las costas de España, cautivado por los españoles y sentenciado a la hoguera por la Inquisición. Parientes suyos en Argel, buscando venganza, compraron a un cautivo, sacerdote de la orden de Montesa, y después de someterlo a tormentos públicos indescriptibles lo quemaron. Esta historia no es invención de Gervantes, ocurrió en 1576-1577 y es relatada con todos sus pormenores en Haedo (t. 3, pp. 139-155).

No cabe duda de que El trato es el drama de cautivos más poderoso de Cervantes. Recién salido de los baños de Argel, pintaba con colores vivos y profunda sensibilidad los horrores de la vida del esclavo cristiano. Nada bueno se encuentra en el ambiente argelino: ". . tierra tan sin concordia, / do falta misericordia / y sobra la crueldad"' (p. 24), donde los morillos en la calle se mofan del cautivo con el cruel e inolvidable estribillo: “ ¿Don Juan no venir; acá morir!'” (p. 61).

Mientras van pasando los años las memorias del sufrimiento se hacen menos intensas y la actitud hacia el renegado menos dura. Los baños de Argel ${ }^{11}$ repite muchas escenas de El trato, pero los españoles aquí tienen más esperanza y mayor valentía. Salen en la obra, por alusión o como personajes, tres renegados históricos, aunque no se les identifica como renegados: Asán Bajá una vez más; Agi Morato, de quien se dice que es "Vn moro de buena masa, / principal y hombre de bien" 12; y Morato Ráez (Maltrapillo), "atrevido"' cosario, el renegado murciano que posiblemente fue amigo de Cervantes. Dos renegados más son invenciones. Isuf (Ysuf en el texto), identificado como renegado español, abre la

10 Oliver Asín, art. cit., pp. 250 y 282.

${ }^{11}$ Sobre la fecha de composición de esta obra no se ha llegado a ningún acuerdo: algunos la creen posterior a 1599 como refundición de Los cautivos de Argel; otros mantienen que Los cautivos es refundición de El trato y de Los baños.

${ }^{12} O C$, t. 1, p. 252. 
obra con un ataque contra un lugar en la costa valenciana; se le condena por ser un traidor sin igual a su tierra natal, Valencia (p. 242). Tres de los presos esa noche son su tío y dos sobrinos (p. 267). El otro renegado, Hazén, es todo lo opuesto. Lo vemos primero solicitando firmas a los cautivos cristianos que atestigüen su buena conducta con ellos porque quiere volver a España y a su fe. Renegó de niño (siempre el peligro en Cervantes) y se ha hecho cosario, pero sostiene ser buen cristiano en lo escondido; confesará su "moço y antiguo yerro; / no como Yzuf, aquel perro / que fue a vender su lugar" (p. 251). Cualquier duda sobre la autenticidad de su convicción se borra inmediatamente cuando se relata cómo ha matado al traidor Yzuf al saber que ha vendido como esclavos a su tío y sus sobrinos. Luego confiesa abiertamente su cristianismo, pide el martirio y lo recibe (pp. 267-270).

Si en El trato el niño Juanico reniega, aquí el niño Francisco, igualmente tentado, nunca vacila en su fe y al fin también sufre el martirio (pp. 324-325). La fe, el no renegar, se ensalza sobre cualquier otro valor para el español valiente, pero es victorioso el espíritu cristiano en Los baños como no lo fue siempre en El trato. Además, la inserción de una versión de la historia de la hija de Agi Morato, mora que quiere pasar al cristianismo, baña la obra de cierta luz romántica nunca presente en El trato, obra más aferrada a la realidad histórica del cautiverio.

Aunque El gallardo español dramatiza el asalto turco (repelido) contra Orán en 1562-1563, se dedica principalmente a seguir la fortuna amorosa de una pareja mora y otra cristiana. Hay renegados no históricos, pero su acción es confusa y no contribuye al desenlace de la obra. El protagonista Fernando de Saavedra pasa la mayor parte del tiempo en un pueblo moro y vestido de moro; creen algunos que ha renegado ${ }^{13}$, pero nosotros sabemos que no es así. Aparece un Asán Bajá, rey de Argel, pero no es el histórico, patrón de Cervantes. Alimuzel, moro antagonista de Fernando, es leal, honrado, fiel a su palabra. Hemos dejado atrás la amargura y el rencor entre cristiano y musulmán que empapan las comedias anteriores. Para apreciar el tono nuevo de esta comedia sólo hay que leer la última escena: los cristianos han vencido, se prometen dulces y alegres fiestas; el gracioso Buytrago, quien ha luchado ferozmente en el combate, quiere comer y grita que si no hay tales fiestas, "Renegaremos"' (p. 130). Chiste inconcebible en los dramas anteriores.

${ }^{13}$ Ibid., p. 54. 
Por las alusiones en La gran sultana doña Catalina de Oviedo a err bajadas persas a la corte de Felipe III que tuvieron lugar en lc años 1605-1611, ésta parece ser una comedia tardía, quizá el últ mo de los dramas turcos de Cervantes ${ }^{14}$. Volvemos a un ambient (Constantinopla) en que se amenaza a cautivos cristianos con fueI tes castigos o muerte; por eso existe la tentación de renegar. Per en vista de que el Gran Turco ${ }^{15}$ queda totalmente embelesado esclavizado por la belleza de la cautiva Catalina, nunca tememo por ella ni por ningún otro cristiano. Es una historia del todo fan tástica; aunque había cautivas cristianas en el serrallo del Gra: Turco, nunca pudo casarse un sultán musulmán con una muje cristiana.

Renegados sí hay en la obra, empezando por un tal Salee qu declara que no cree en ninguna religión, provocando a su amig cristiano Roberto a decir que es un "fino ateísta" "16. Recuérde se la caracterización de Mahamet, el judío renegado en Argel, co mo "impío ateo" (citado supra). Sin embargo, promete -y lograSalec ayudar a Roberto a encontrar a su joven amigo Lambertı en la ciudad. En cambio, un renegado eunuco, Mamí, muestr. su mala fe delatando al Gran Turco el secreto de la presencia d la bella Catalina en su serrallo. Y de los renegados históricos $\mathbf{S}$ menciona una vez más a Morato Ráez Maltrapillo, quien segú la ficción del drama, habiendo cautivado a Catalina de niña, des pués la regaló al Gran Turco (pp. 123 y 193-194); y muy de pası se alude al renegado calabrés Uchalí, protector de Asán Bajá (p 132). Vuelve, bastante reducido y apagado, el sermón predicadı en El trato: por ninguna razón puede renegar el cristiano auténti co. Madrigal, cautivo cristiano, un hidalgo pobre, proclama pri mero con enorme orgullo que su voluntad es férrea porque es es pañol, y lo será por los siglos de los siglos (p. 131); por ende e natural que cuando es sorprendido en la cama con una mora : condenado a muerte, no acepte la solución de dejar la ley que ador:

14 Jean Canavaggio, Cervantès dramaturge. Un théâtre à naître, P.U.F., Pa ris, 1977 , p. 397.

${ }^{15}$ Es bien posible que este Gran Turco, tan "europeizado" en sus gus tos y costumbres, se inspire en la figura de Muley Maluco ('Abd al-Malik) de origen marroquí, que por la guerra se hizo sultán de Marruecos en 1576 dos años después de su matrimonio con Zahara, la hija de Agi Morato. $S_{1}$ alaba en Los baños de Argel como "liberal, sabio, compuesto, / de mil gracia adornado" (p. 334) y gran conocedor de los idiomas y costumbres europeos Oliver Asín, art. cit., pp. 256-277, habla largamente de este marroquí.

${ }^{16} O C$, t. 2, p. 118. 
para casarse con la mora (pp. 142-143). Por su astucia Madrigal elude la muerte, burlándose de los turcos.

En el caso de Catalina, lo que se rechaza es el martirio, tan exaltado en Trato y Baños. En ningún momento piensa Catalina de Oviedo en renegar - ni la fuerza a hacerlo el Gran Turcopero no quiere ella casarse, contra las reglas de su fe, con un musulmán. Rustán, el eunuco cristiano, emplea una vez más el argumento de que cuando se ejerce fuerza como en este caso, "no está el pecado en el hecho, / si en la voluntad no está: / condénanos la intención / o nos salua en quanto hazemos"; contesta ella " antes morir que pecar", a lo que responde Rustán: "Ser mártir se ha de causar / por más alto fundamento, / que es por el perder la vida / por confessión de la fe" (pp. 152-153). Más tarde pensará Catalina en suicidarse para evitar el matrimonio, pero pronto se convence de que el peor pecado de todos es desesperarse. Quedándose cristiana en el corazón y en el vestido, se casa con el Gran Turco, consiguiendo así el poder para hacer mucho bien a los cristianos: se la exalta al final de la obra como "gran sultana y christiana, gloria y honra / de sus pequeños y christianos años, / honor de su nación y de su patria" (p. 217).

Por consiguiente, lo que parecía en un momento ser una repetición del mensaje de Trato y Baños ha acabado en armonía y no en combate religioso. ¿ Revela esta fantasía un sueño acariciado por Cervantes de ver el fin del antagonismo religioso entre el imperio otomano y el español?

El estudio más matizado y complicado del renegado se encuentra en el relato del Capitán Cautivo, Ruy Pérez de Biedma, en los caps. 39-41 del Quijote de 1605, escrita esta sección de la obra posiblemente en $1590^{17}$. Como en las obras ya estudiadas, aparecen alusiones a renegados estrictamente históricos (aunque a veces, para realizar los fines de la ficción, se introducen leves cambios, especialmente cronológicos, en sus vidas), a renegados históricos casi totalmente transformados que actúan plenamente como personajes en el relato y a renegados inventados por Cervantes. Claro está que cuando el renegado histórico entra en las páginas de un drama o una novela será en alguna medida diferente del personaje histórico.

Entre el primer grupo se encuentra Uchalí Fartax (el tiñoso),

17 Para la fecha de composición véase Miguel de Cervantes SaAvedra, El ingenioso hidalgo Don Quijote de la Mancha, ed. Luis Andrés Murillo, Castalia, Madrid, 1978, t. 1, pp. 472-473, n. 1. 
quien, según nos cuenta el Capitán, "bogó el remo, siendo esclavo del Gran Señor, catorce años, y a más de los treinta y cuatrc de sus edad renegó, de despecho de que un turco, estando al remo, le dio un bofetón, y por poderse vengar, dejó su fe"' (p. 484). Por primera vez vemos a un renegado cuyo abandono de la $f \epsilon$ parece justificado. Procede el Capitán a relatar con admiración las hazañas de Uchalí, para terminar así: "Era calabrés de nación, y moralmente fue hombre de bien $\mathrm{y}$ trataba con mucha humanidad a sus cautivos"'18. En un sentido Cervantes ha hecho personaje de su cuento a Uchalí, porque según la ficción éste había tomado preso a Biedma; y después se falsifica el año de la muerte del renegado (realmente ocurrida en 1587), dándola como ocurrida en 1574, quizá para poder explicar la llegada del Capitán a Argel: según el cuento, Asán Agá hereda al Capitán al morirse Uchalí y luego le lleva consigo al ser nombrado rey de Argel en 1577. Este Asán es el renegado veneciano, patrón de Cervantes cuando fue rescatado, a quien hemos visto ya muchas veces (jqué deleite habrá sentido Cervantes en hacer a su amo mero títere de sus ficciones!). El Capitán declara que "él vino a ser el más cruel renegado que jamás se ha visto” (p. 485), cruel por el gusto de ser cruel, "por ser natural condición suya ser homicida de todo el género humano"' (p. 486). Hay además breves alusiones a Arnaute Mamí, el renegado albanés (que cité anteriormente), identificado aquí como grandísimo amigo de Agi Morato (p. 496), y a la crueldad del hijo (realmente nieto) de Barbarroja (p. 479). Vale la pena recordar que el primer Barbarroja azote del Mediterráneo, fue un renegado griego ${ }^{19}$.

El renegado inventado por Cervantes desempeña un papel importantísimo en el relato. Es un murciano (recuérdese al renegado murciano Maltrapillo, amigo de Cervantes) que, deseando volver a su tierra, ha conseguido la firma de muchos cautivos cristianos en los documentos en que se alega su buena fe y buen trato dado a los cristianos; se añade que no es de esos que piden firmas para ir luego a robar a tierra de cristianos, porque "si a dicha se pierden o los cautivan, sacan sus firmas" para probar su intención de quedarse en tierra de cristianos, logrando así escaparse de la justicia "y se reconcilian con la Iglesia, sin que se les ha-

18 Ibid., p. 484, las cursivas son mías; HaEdo (op. cit., t. 1, pp. 346-361) da la misma explicación de la apostasía de Ochalí y se extiende mucho en relatar sus hazañas.

${ }^{19}$ Diego de HaEdo, op. cit., t. 1, p. 213. 
ga daño; y cuando veen la suya, se vuelven a Berbería a ser lo que antes eran' (p. 489). Es este renegado quien traduce las cartas de la bella mora Zorayda y compra el barco en que escapan él mismo, ella, el Capitán y otros cristianos. En suma, es él quien por sus buenos consejos, honradez y astucia hace posible el feliz desenlace del cuento. (Igual papel se le da al renegado Mahamut en El amante liberal, activo en todo momento para lograr que escapen con él de Nicosia, el protagonista, su amada y la renegada griega Halima. La pareja renegada se reconcilia con la iglesia en Sicilia y se casan.)

Como todos saben, el relato al parecer tan histórico del Capitán pasa luego a la esfera romántica con la inventada historia de la mora, hija de Agi Morato, que quiere huir de Argel para ser cristiana, adoptando la fe que le enseñó una esclava, ya muerta, que vivió en su casa. Otra versión de esta trama, como ya se ha observado, se encuentra en Los baños de Argel.

Uno de los aspectos más significativos de esta historia inventada es la extraña intrusión de hechos históricos. Zoraida no es la hija de cualquier turco sino de un personaje bien conocido en Argel (y bien conocido de Cervantes), Agi Morato, rico renegado esclavón, dueño de un palacio y jardines espléndidos, alcaide de La Bata en Argel en 1581 y suegro de Muley Maluco, rey de Marruecos. Se había casado Agi Morato con la hija de un renegado mallorquín, de manera que la "Zoraida" histórica fue nieta de cristianos ${ }^{20}$.

De la verdad histórica conserva Cervantes solamente la identificación de Agi Morato como "moro principal y rico, alcaide que había sido de La Pata" (p. 488). Nada se dice en el relato del Capitán, tan lleno de personajes renegados, del origen cristiano de Agi Morato o de su hija. ¿Por qué? Obviamente para evitar que viéramos una especie de justicia poética en la escena crucial del relato cuando Agi Morato es abandonado por su hija a causa de la religión: es decir, considerar que la "apostasía" de la hija sea justo castigo por la apostasía del padre.

Cervantes ha creado a un Agi Morato generoso, comedido, tierno y cariñoso padre, y moralmente hombre de bien, aunque era musulmán. ¿Quién puede leer el intercambio entre el padre

${ }^{20}$ Para más informes sobre el Agi Morato histórico y la supresión o cambio por Cervantes de la realidad histórica de Zoraida y su padre, véase el artículo ya citado de Oliver Asín. Francisco Márquez Villanueva dedica a la caracterización de Zoraida y su psicología un espléndido estudio en Personajes y temas del "Quijote", Taurus, Madrid, 1975, pp. 92-146. 
abandonado y la hija que huye sin compadecer a aquél? Empieza Agi Morato culpándola, atribuyendo su cambio de fe no al hecho de que el cristianismo sea mejor que el Islam, "sino el saber en vuestra tierra se usa la deshonestidad más libremente que en la nuestra" (es algo irónico que tantas veces se haya dicho que por este mismo motivo muchos cristianos pasaron al Islam). ¿Cómo puede ella irse "en poder destos perros, naturales enemigos nuestros"? Pero poco después, viendo alejarse rápidamente el bajel con su hija, dice, en palabras conmovedoras que hacen eco del lamento de Pleberio en la Celestina: " " $i$ Vuelve, amada hija, vuelve a tierra, que todo te lo perdono [...] vuelve a consolar a este triste padre tuyo, que en esta desierta arena dejará la vida, si tú le dejas!»". Lo único que sabe contestar Zoraida es que el vivo impulso de la fe en su corazón la fuerza a "poner por obra esta que a mí me parece tan buena como tú, padre amado, la juzgas por mala" (p. 507). Se deja al lector decidir si la fe religiosa justifica tal crueldad humana. En la esfera moral que pueden compartir los creyentes de diversas religiones, quien sale victorioso aquí es Agi Morato.

Seguimos ahora los pasos de Zoraida y sus compañeros, que después de muchos infortunios llegan a Vélez Málaga, ella todavía en traje de mora, "pero en el alma [...] muy grande cristiana" (p. 463). Y se acaba todo con la esperanza consoladora de la recepción en el futuro por la Iglesia de dos renegados: la mora, debidamente catequizada en su nueva fe, y el cristiano renegado, quien "hecha su información de cuanto le convenía, se fue a la ciudad de Granada a reducirse por medio de la Santa Inquisición al gremio santísimo de la Iglesia" (p. 513).

Ya se ha observado que El gallardo español y La gran sultana tratan las divisiones religiosas con mucho menos rencor que los dramas anteriores. En la novela ejemplar tardía La española inglesa (quizá escrita en 1611), aunque hay duros conflictos entre cosarios turcos e ingleses (Arnaute Mamí, el renegado albanés, aparece una vez más), Ricardo, el protagonista, cautivo en Argel, debe su vida a la honradez de un turco (años antes cautivado y generosamente liberado por Ricardo) que no revela la identidad del cosario inglés por "tan agradecido y tan hombre de bien" 21 . Pero ya en 1590, en el relato del Capitán Cautivo, Cervantes había llegado a una percepción compleja del significado del conflicto religioso y del fenómeno del renegado. Las religiones nos dividen,

${ }^{21} O C$, Novelas ejemplares, t. 2, p. 69. 
mientras que la conducta moral generosa une a todos los hombres civilizados. Queda resonando en nuestros oídos el juicio sobre el renegado Uchalí, quien a pesar de su religión, "moralmente fue hombre de bien'”.

WILLARD KING

Bryn Mawr College 
